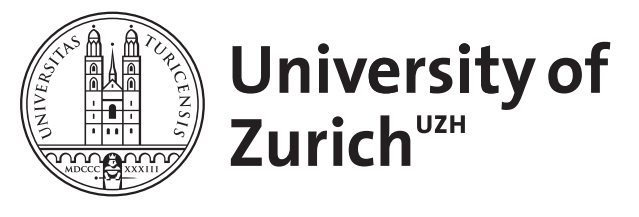

\title{
Biomarkers in renal cancer
}

Moch, Holger ; Srigley, John ; Delahunt, Brett ; Montironi, Rodolfo ; Egevad, Lars ; Tan, Puay Hoon

\begin{abstract}
Treatment options for primary and metastatic renal cancer are increasing. Accurate data from the pathological examination of renal cancer specimens aid clinicians in stratifying patients for surveillance and adjuvant therapies. This review focuses on biomarkers in diagnosis, prognosis and prediction of the biologic behavior of renal tumors which should be recorded in pathology reports and which are under investigation. Special emphasis is given to the use of immunohistochemical markers in differential diagnosis of various renal tumor subtypes. The relevance of cytogenetic and molecular findings is also discussed. The review includes the 2012 International Society for Urological Pathology Consensus conference recommendations.
\end{abstract}

DOI: https://doi.org/10.1007/s00428-014-1546-1

Posted at the Zurich Open Repository and Archive, University of Zurich

ZORA URL: https://doi.org/10.5167/uzh-96273

Journal Article

Published Version

Originally published at:

Moch, Holger; Srigley, John; Delahunt, Brett; Montironi, Rodolfo; Egevad, Lars; Tan, Puay Hoon (2014). Biomarkers in renal cancer. Virchows Archiv, 464(3):359-365.

DOI: https://doi.org/10.1007/s00428-014-1546-1 


\title{
Biomarkers in renal cancer
}

\author{
Holger Moch • John Srigley • Brett Delahunt • \\ Rodolfo Montironi • Lars Egevad • Puay Hoon Tan
}

Received: 11 November 2013 /Revised: 6 January 2014 / Accepted: 14 January 2014 / Published online: 1 February 2014

(C) Springer-Verlag Berlin Heidelberg 2014

\begin{abstract}
Treatment options for primary and metastatic renal cancer are increasing. Accurate data from the pathological examination of renal cancer specimens aid clinicians in stratifying patients for surveillance and adjuvant therapies. This review focuses on biomarkers in diagnosis, prognosis and prediction of the biologic behavior of renal tumors which should be recorded in pathology reports and which are under investigation. Special emphasis is given to the use of immunohistochemical markers in differential diagnosis of various renal tumor subtypes. The relevance of cytogenetic and molecular findings is also discussed. The review includes the 2012 International Society for Urological Pathology Consensus conference recommendations.
\end{abstract}

\footnotetext{
H. Moch $(\bowtie)$

Institute of Surgical Pathology, University Hospital Zurich,

Schmelzbergstrasse 12, CH-8091 Zürich, Switzerland

e-mail: holger.moch@usz.ch

J. Srigley

Department of Pathology and Molecular Medicine, McMaster

University, Hamilton, ON, Canada

B. Delahunt

Department of Pathology and Molecular Medicine, University of Otago, Wellington, New Zealand

R. Montironi

Section of Pathological Anatomy, Polytechnic University of the Marche Region, School of Medicine, United Hospitals, Ancona, Italy

L. Egevad

Department of Oncology-Pathology, Karolinska Institutet,

Stockholm, Sweden

P. H. Tan

Department of Pathology, Singapore General Hospital, Singapore,

Singapore
}

Keywords RCC $\cdot$ Staging $\cdot$ Grading $\cdot$

Immunohistochemistry $\cdot$ Biomarker $\cdot$ Molecular pathology

\section{Introduction}

Biomarkers in renal cell carcinoma (RCC) are of help in pathological diagnosis, classifying new entities, and include predictive and prognostic markers. Immunohistochemistry allows the characterization of renal tumor subtypes, whereas novel molecular analyses are mainly used to characterize specific molecular pathways involved in different tumor subtypes. They are also useful to identify potential therapeutic targets. This article will review the key prognostic factors with an emphasis on the use of immunohistochemical markers in routine practice. The review is intended to complement the International Society of Urological Pathology (ISUP) conference on renal cancer held in Vancouver in 2012 [1, 2].

\section{Old and new subtypes of renal cell neoplasms}

In adults, the main morphotype of RCC, when correctly classified, is the strongest prognostic biomarker in addition to tumor stage and grade $[3,4]$. The current World Health Organization Classification of Renal Tumors was established 2004 [5]. In adults, the main subtypes are clear cell, papillary, chromophobe, collecting duct, and unclassified RCC, but various other subtypes have been recognized in the 2004 WHO classification, including mixed epithelial and stromal tumors (MEST), mucinous tubular and spindle-cell carcinoma (MTSC), and translocation cancer. Oncocytoma, angiomyolipoma, and metanephric adenoma are considered benign renal neoplasms. At the ISUP conference, a consensus was reached to recognize five entities as new distinct epithelial tumors: tubulocystic RCC, acquired cystic disease-associated 
RCC, clear cell (tubulo) papillary RCC, the MiT family translocation RCCs (including $\mathrm{t}(6 ; 11) \mathrm{RCC}$ ), and hereditary leiomyomatosis RCC syndrome-associated RCC. Thyroidlike follicular RCC, succinate dehydrogenase B deficiencyassociated RCC and ALK translocation RCC were regarded as emerging new entities (Figs. 1, 2 and 3) [1]. Subtyping of papillary RCC (types 1 and 2) provides additional prognostic information. For the time being, the oncocytic variant of papillary RCC is not considered as a distinct entity. Clear cell (tubulo)papillary RCC is associated with a more favorable outcome. Multicystic clear cell RCC is considered as a neoplasm of low malignant potential within the group of clear cell RCC. The hybrid oncocytic chromophobe tumor occurs in Birt-Hogg-Dubé Syndrome, in renal oncocytosis and also as a sporadic neoplasm. Hybrid oncocytic chromophobe tumors are indolent tumors grouped, at least for the time being, in the chromophobe RCC category. Epitheloid angiomyolipoma is nowadays considered a potentially malignant variant of angiomyolipoma, because metastatic disease has been reported in some patients with this specific subtype of angiomyolipoma. Cystic nephroma and mixed epithelial and stromal tumor are seen as a morphological spectrum within a single tumor type [1].

\section{Perinephric fat invasion as a staging parameter}

The 2009 TNM system has minor changes compared to the 2002 TNM system, notably in clarifying that infiltration of renal sinus (peripelvic) fat is part of perinephric tissue involvement in the pT3 tumor category [6,7]. Perinephric fat invasion is prognostically relevant, as it is associated with a significant decrease in 5-year overall survival [8]. Perinephric fat invasion was defined at the 2012 ISUP conference as either the tumor touching the fat or extending with irregular tongues into the perinephric tissue, with or without desmoplasia [9]. Importantly, recent studies have shown the relevance of renal sinus invasion in renal cancer $[10,11]$. The frequent renal sinus invasion in early-stage tumors has been overlooked for many years, but has significant prognostic implications. Renal sinus invasion is present when the tumor is in direct contact with the fatty tissue or the loose connective tissue of the sinus. Involvement of any endothelial lined spaces within the renal sinus is considered as renal sinus invasion, regardless of the size of the vascular space [9].

\section{Tumor grade, sarcomatoid differentiation, and necrosis as prognostic biomarkers of renal cancer}

The Fuhrman grading system has been in use for over 30 years and is still the most widely utilized grading system for renal cancer [12]. Nonetheless, it has not evolved over the years to accommodate our increasing understanding of the nature and biological spectrum of renal carcinoma. Furthermore, its use has become controversial, as it is increasingly recognized that its application is not without problems [13, 14]. In addition, the grading system has not been validated for many of the morphotypes of renal cell carcinoma. In view of the problems associated with the application of Fuhrman grading, a new grading system was endorsed at the recent ISUP consensus conference [3]. Nucleolar prominence defines grades 1 to 3 of clear cell and papillary RCCs, whereas extreme nuclear pleomorphism or sarcomatoid and/or rhabdoid differentiation defines grade 4 tumors. The ISUP grading system was endorsed as a prognostic parameter for clear cell renal cell carcinoma. In addition, a consensus was reached that chromophobe RCC should not be graded [15-17], as irregular nuclei, prominent nucleoli, and nuclear pleomorphism are inherently present in chromophobe RCC, even in cases with good prognosis [3].

Different grading systems for chromophobe RCC have been proposed [15], but these were not endorsed at the 2012 ISUP consensus conference. Sarcomatoid and/or rhabdoid differentiation and tumor necrosis were accepted as useful
Fig. 1 Mucinous tubular and spindle-cell carcinoma showing classical pattern with elongated tubules, spindle-cell areas, and stromal mucin

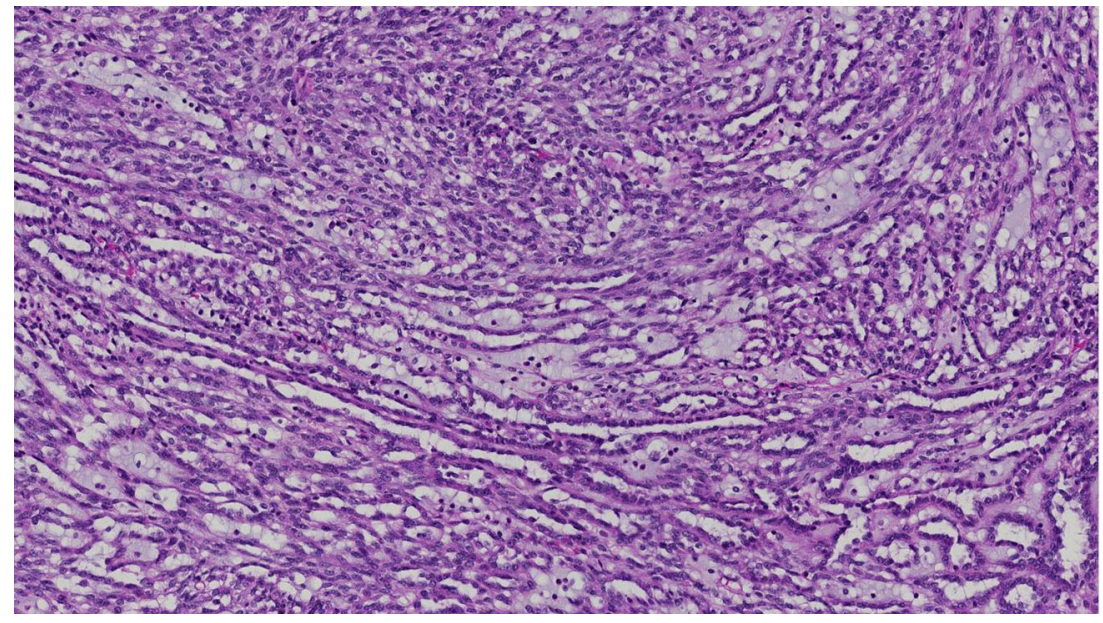


Fig. 2 New tumor entity: leiomyomatous renal cell carcinoma. Note nests and tubules lined by clear cells embedded in smooth muscle

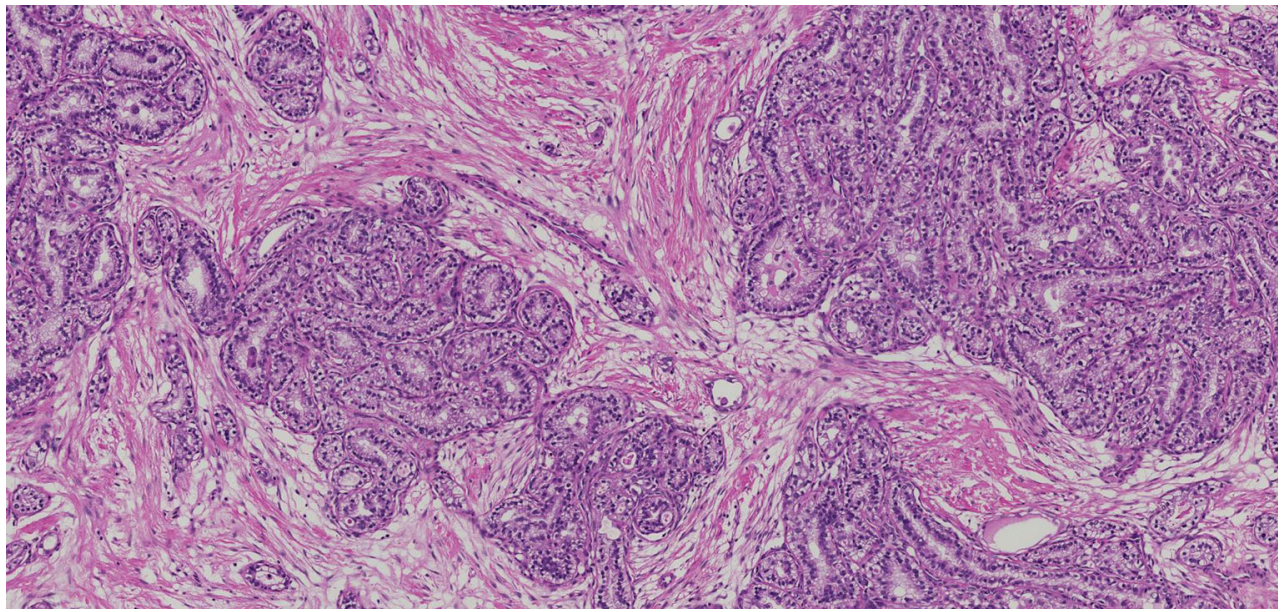

additional histopathologic prognostic parameters [4]. Sarcomatoid or rhabdoid differentiation should be mentioned in pathology reports of all RCC subtypes. For a correct tumor classification, the underlying carcinoma subtype should be reported, because this can be recognized for all main subtypes. If the underlying carcinoma subtype cannot be recognized in sarcomatoid RCC, the tumor should be classified as a grade 4 unclassified carcinoma with a sarcomatoid component. Tumor necrosis is considered of prognostic significance and the amount of necrosis should be quantified in clear cell RCC. In contrast, intratumoral microvascular invasion should not be included as a staging criterion for RCC $[4,9]$.

RCC is considered to be susceptible to the innate and adaptive immune responses of the host because a small subset of patients with advanced disease achieves spontaneous or immunotherapy-induced complete remission. The cellular and molecular mechanisms underlying these complete remissions are not completely understood, although a variety of inflammatory cells including $\mathrm{T}$ and Natural killer (NK) cells

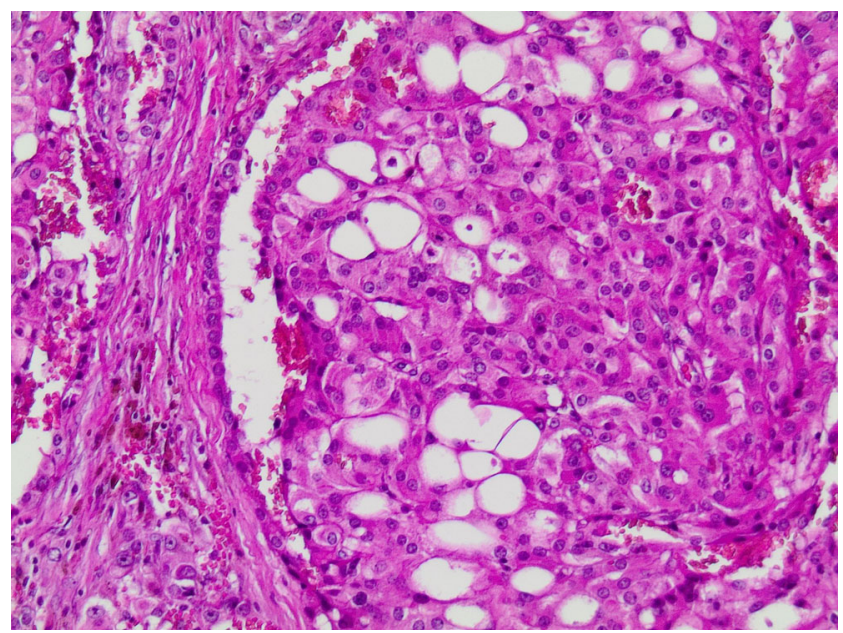

Fig. 3 New tumor entity: Renal cell carcinoma in end-stage renal disease. Note cytoplasmic vacuolation have been identified in RCC lesions. Local immunoregulatory processes may have an impact on disease progression and therefore on survival of patients with primary clear cell renal cell carcinoma. Earlier data have shown that a high number of tumor-infiltrating lymphocytes and/or macrophages are associated with poor prognosis [18-20].

\section{Differential diagnosis of renal cell neoplasms using immunohistochemical biomarkers}

Most renal cancer subtypes have a characteristic immunohistochemical staining profile that helps in the correct tumor classification. It has been shown that upregulation of CD10 and Pax 2 expression is due to VHL inactivation in clear cell RCC [21, 22], while CAIX is also consistently expressed due to its regulation by the VHL protein [23, 24]. Papillary RCC type 1 stains for vimentin, broad spectrum keratins, CK7, AMACR and RCC marker, but not for CD117, kidneyspecific cadherin, and parvalbumin. Papillary RCC type 2 has variable staining patterns. Whereas papillary type $1 \mathrm{RCC}$ frequently show diffuse CK 7 immunoreactivity, papillary type $2 \mathrm{RCC}$ are less often positive for $\mathrm{CK} 7$, in a staining pattern comparable to that of clear cell RCC with only focal CK7 expression. Chromophobe RCC are negative for vimentin (Table 1), but show diffuse reactivity for E-cadherin, kidneyspecific cadherin, parvalbumin, CD117, EMA, broad spectrum keratins, and CK7 $[1,4]$. To differentiate between benign oncocytoma and chromophobe RCC, specifically its eosinophilic variant, is difficult as these tumors have overlapping histological and immunohistochemical characteristics. CK7 is the best marker to differentiate between these two tumor entities. Most chromophobe RCCs show membranous CK7 expression in tumor cell clusters or in the majority of tumor cells while oncocytoma is typically negative or at most focally positive in scattered cells $[25,26]$. Other biomarkers useful for this differential diagnosis are summarized in Table 2. 
Table 1 Biomarkers in clear cell and chromophobe RCC

\begin{tabular}{lll}
\hline Biomarker & Clear cell RCC & Chromophobe RCC \\
\hline CK7 & - (focal) & + \\
RCC marker & + & - \\
CD10 & + & - \\
Vimentin & + & - \\
CD117 & - & + \\
Parvalbumin & - & + \\
E-cadherin & - & + \\
EMA & + & + \\
MUC1 & + & + \\
CK20 & - & - \\
AMACR & - & - \\
\hline
\end{tabular}

Collecting duct carcinomas often show immunoreactivity for EMA, CK7, high molecular weight keratin, Pax 2 and/or Pax 8 [27] (Table 3). Pax 2 and/or Pax 8 are frequently expressed in different renal carcinoma subtypes and represent useful markers in the differential diagnosis of a primary renal carcinoma, although expression patterns need to be interpreted in conjunction with other markers. For instance, expression of Pax 8 has been reported in primary pancreatic neuroendocrine tumors, which can mimic metastatic RCC [28]. Distinction from RCC will therefore require additional support, including the lack of expression of neuroendocrine markers for a diagnosis of RCC. There is consensus that TFE3 and TFEB immonostains should be requested in order to diagnose RCC in a young patient or when histological appearances are suggestive of the translocation subtype of RCC [4].

Epitheloid angiomyolipoma closely resembles RCC [3, 29]. Positive immunoreactivity for HMB45, melan-A and SMA, and absence of expression of keratins, helps in the diagnosis of angiomyolipoma [30]. Metanephric adenoma can be mistaken for type 1 papillary RCC. The former shows positive immunostaining for WT1, CD57, and absence of

Table 2 Biomarker in chromophobe RCC and oncocytoma

\begin{tabular}{lcc}
\hline Biomarker & Chromophobe RCC & Oncocytoma \\
\hline CK7 & + & - focal + \\
MOC31 & + & - \\
EpCam & + & - \\
Caveolin-1 & + & - \\
EABA & - & + \\
CD82 & + & - \\
S100A1 & - & + \\
Parvalbumin & + & + \\
Ksp cadherin & + & + \\
CD117 & + & + \\
\hline
\end{tabular}

Table 3 Biomarker for poorly differentiated carcinomas

\begin{tabular}{llll}
\hline Antibody & $\begin{array}{l}\text { RCC, } \\
\text { unclassified }\end{array}$ & $\begin{array}{l}\text { Collecting duct } \\
\text { carcinoma }\end{array}$ & $\begin{array}{l}\text { Urothelial } \\
\text { carcinoma }\end{array}$ \\
\hline CK7 & $-/+$ & + & + \\
CK20 & - & $-($ rarely focal +$)$ & $+/-$ \\
P63 & - & $-($ rarely +$)$ & + \\
RCC & $+/-$ & - & - \\
Vimentin & $+/-$ & + & $-/+$ \\
CD10 & $+/-$ & - & $-/+$ \\
CK5/6 & - & - & $+/-$ \\
INI1 & + & + & + \\
Ulex-1 & - & + & $-/+$ \\
PAX8 & $+/-$ & + & $-/$ rarely + \\
PAX2 & $+/-$ & $+/-$ & - \\
GATA3 & $-/($ rarely focal + ) & - & + \\
\hline
\end{tabular}

reactivity for AMACR [31]. AMACR, CK7, WT1, and $\mathrm{CD} 57$ are therefore useful to distinguish metanephric adenoma from papillary RCC (Table 4).

\section{Molecular prognostic biomarkers}

Biomarkers for potential prognostication of RCC include molecules in intracellular pathways and/or specific DNA alterations. Most of them have not entered clinical practice. Clear cell RCC is characterized by loss of chromosome $3 p$ and mutations of the von Hippel Lindau (VHL) gene [32]. VHL mutations have been reported in the majority of sporadic clear cell renal carcinomas [33]. These mutations can impact on the hypoxia inducible factor (HIF) pathway and their existence provides the theoretical molecular explanation for the success of HIF targeted treatment strategies in some patients with clear cell RCC (see below) [34, 35]. Dysregulation of HIF leads to upregulation of the expression of downstream molecules, including Carbonic anhydrase 9 (CAIX). One study found an association between CAIX expression and grade of clear cell RCC [36]. Diminished CAIX expression was independently correlated with poor survival in advanced renal cell cancer patients [37]. Some other chromosomal abnormalities may have prognostic value, such as loss of chromosome $9 p$ in clear cell RCC, which is associated with a significantly poorer cancer specific survival $[38,39]$

A relatively new finding is the frequent polybromo-1 (PBRMI) and BAP 1 mutation on chromosome $3 \mathrm{p}$ in a surprisingly high percentage of clear cell RCC [40]. Loss of PBRM1 protein expression product BAF180 was shown to be associated with advanced tumor stage and worse patient outcome [41]. All of these newly identified mutations target 
Table 4 Biomarker for renal tumors with papillary or tubulopapillary architecture

\begin{tabular}{|c|c|c|c|c|c|}
\hline Antibody & $\begin{array}{l}\text { Papillary } \\
\text { RCC }\end{array}$ & $\begin{array}{l}\text { Collecting duct } \\
\text { carcinoma }\end{array}$ & $\begin{array}{l}\text { Metanephric } \\
\text { adenoma }\end{array}$ & $\begin{array}{l}\text { Mucinous tubular and } \\
\text { spindle-cell carcinoma }\end{array}$ & $\begin{array}{l}\text { Clear cell } \\
\text { papillary RCC }\end{array}$ \\
\hline CK7 & + & + & $\begin{array}{l}- \text { (only } \\
\text { focal) }\end{array}$ & + & + (diffuse) \\
\hline CD10 & + & - & - & $-/+$ & - \\
\hline $\mathrm{RCC}$ & + & - & - & variable & $-1+$ \\
\hline AMACR & + & - & $-/+$ & + & - \\
\hline EMA/MUC1 & + & + & $\begin{array}{l}- \text { (may be } \\
\text { focal) }\end{array}$ & + & + \\
\hline WT1 & - & - & + & - & - \\
\hline CD57 & - & No data & + & - & No data \\
\hline Ulex-1 & - & + & - & - & No data \\
\hline
\end{tabular}

genes which are responsible for chromatin remodeling. Future studies will help to understand the tumor suppressor gene network between $V H L$ and the other genes on chromosome $3 \mathrm{p}$. Compared to other solid tumors, intratumoral heterogeneity of driver gene mutations is very pronounced within primary $\mathrm{RCC}$ as well as between primary tumors and their metastases $[42,43]$. The process of clonal evolution of renal cancer cells is very complex, and this has potential consequences for tumor progression, development of resistance against targeted therapies, with clinical impact.

Papillary RCC is characterized by numerical abnormalities, often trisomies of chromosomes 7 and 17 [44]. Chromophobe RCCs harbor multiple numerical losses of chromosomes 1, 2, 6,10 , and 17 [45]. Translocation RCCs are defined by translocations involving chromosome Xp11.2, resulting in TFE3 gene fusions [46]. Another variant of translocation associated RCC is characterized by fusion of the TFEB gene on chromosome $6 \mathrm{p}$ with the alpha gene on $11 \mathrm{q} 12$, which leads to expression of the TFEB protein $[47,48]$.

Cytogenetics and novel molecular technologies are rarely used in renal carcinoma diagnosis, but have contributed to tumor classification, understanding the histogenesis and the genotype/ phenotype correlation in RCC. Some groups recommend a panel of fluorescence in situ hybridization (FISH) probes for the differential diagnosis of RCC. For instance, numerical abnormalities of chromosomes 7 and 17 on FISH favor a diagnosis of papillary RCCs over clear cell RCC. The value of FISH in diagnosing a translocation RCC with equivocal immunohistochemical results has recently been emphasized [49].

\section{Predictive markers in renal cancer}

Predictive markers provide information on whether a particular cancer will respond to or be resistant to a specific type of therapy. In contrast to other solid tumors, e.g., lung and colorectal cancer or melanoma, use of predictive biomarkers for clinical stratification and management planning has not yet entered routine practice in metastatic renal cancer [4, 50, 51]. In 2007, six new agents, which target complex molecular pathways regulating tumor angiogenesis and cell proliferation and survival, have been approved. These treatments have significantly improved survival times in metastatic renal cell carcinoma [52]. Patients with advanced clear cell $\mathrm{RCC}$ receive VEGF pathway antagonists, e.g., sunitinib or pazopanib. Analysis of $V H L$ mutation status, plasma CAIX, VEGF, sVEGFR2, tissue inhibitor of metalloproteinase 1 (TIMP-1), and Rasp21 has been performed in the TARGET trial comparing sorafenib with placebo in advanced RCC [53]. No predictive markers were identified [54, 55]. Choueiri and colleagues evaluated tumor CAIX expression using immunohistochemistry in patients treated with antiangiogenic therapies [56]. While CAIX expression was neither prognostic nor predictive of response to sunitinib, for sorafenib-treated patients, high CAIX expression $(>85 \%)$ was associated with decreased tumor size in response to treatment.

MicroRNAs (miRNAs, miRs) are small (19-25 nucleotides), non-coding RNAs that play an important role in apoptosis, survival, proliferation, and differentiation processes, by the post-transcriptional regulation of gene-expression. An increasing body of evidence suggests that micro RNA's play a crucial role, not only as oncogenic or tumor-suppressive molecules in cancer initiation, progression and metastasis, but also in resistance to chemotherapy or other systemic therapies. Therefore, miRNA's might constitute potential prognostic and/or predictive biomarkers. Prognostic miRNA expression patterns have recently been identified in RCC tissues [57, 58]. High levels of miR-210 were noticed in chemotherapy resistant ccRCC patients [59]. Downregulation of miR-141 was correlated with lack of response to sunitinib treatment in ccRCC patients, when compared to the expression profile in responding patients [60]. Gamez-Pazo and other groups provided evidence that the response of metastatic ccRCC patients to TKI inhibitors is correlated with a miRNA profile in patient serum [61-63]. 


\section{Conclusion}

Correct tumor classification, histologic grading and systematic examination of radical nephrectomy or tumorectomy specimen are essential for patient management. Tumor stage, tumor type, and tumor grade are robust and independent histopathological prognostic factors, which should be routinely included in pathology reports. Evidence for other prognostic biomarker is lacking. In contrast to other cancers, e.g., lung and colorectal carcinomas or melanoma there are at present no predictive molecular biomarker, suitable for routine use. Future investigation of recently identified novel molecular alterations and tumor suppressor networks in clear cell RCC will help to clarify the biological relevance of different molecular signaling pathways in predicting therapy response.

\section{References}

1. Srigley JR, Delahunt B, Eble JN et al (2013) The International Society of Urological Pathology (ISUP) Vancouver classification of renal neoplasia. Am J Surg Pathol 37:1469-1489

2. Delahunt B, Egevad L, Montironi R et al (2013) International Society of Urological Pathology (ISUP) consensus conference on renal neoplasia: rationale and organization. Am J Surg Pathol 37:1463-1468

3. Delahunt B, Cheville JC, Martignoni G et al (2013) The International Society of Urological Pathology (ISUP) grading system for renal cell carcinoma and other prognostic parameters. Am J Surg Pathol 37: 1490-1504

4. Tan PH, Cheng L, Rioux-Leclercq N et al (2013) Renal tumors: diagnostic and prognostic biomarkers. Am J Surg Pathol 37:1518-1531

5. Eble J, Sauter G, Epstein J et al (2004) Tumours of the kidney, tumours of the urinary system and male genital organs. WHO classification of tumours. IARC, Lyon

6. UICC: TNM Classification of Malignant Tumours (ed 7th), WileyBlackwell, 2009

7. UICC (2002) TNM classification of malignant tumours, 6th edn. Wiley, New York

8. Moch H, Artibani W, Delahunt B et al (2009) Reassessing the current UICC/AJCC TNM staging for renal cell carcinoma. Eur Urol 56: 636-643

9. Trpkov K, Grignon DJ, Bonsib SM et al (2013) Handling and staging of renal cell carcinoma: the International Society of Urological Pathology consensus (ISUP) conference recommendations. Am J Surg Pathol 37:1505-1517

10. Bonsib SM (2005) T2 clear cell renal cell carcinoma is a rare entity: a study of 120 clear cell renal cell carcinomas. J Urol 174:1199-1202, discussion 1202

11. Bonsib SM (2006) Renal lymphatics, and lymphatic involvement in sinus vein invasive (pT3b) clear cell renal cell carcinoma: a study of 40 cases. Mod Pathol 19:746-753

12. Fuhrman S, Lasky L, Limas C (1982) Prognostic significance of morphologic parameters in renal cell carcinoma. Am J Surg Pathol 6:655-663
13. Delahunt B (2009) Advances and controversies in grading and staging of renal cell carcinoma. Mod Pathol: Off J U S Can Acad Pathol, Inc 22(2):S24-S36

14. Delahunt B, Sika-Paotonu D, Bethwaite PB et al (2011) Grading of clear cell renal cell carcinoma should be based on nucleolar prominence. Am J Surg Pathol 35:1134-1139

15. Paner GP, Amin MB, Alvarado-Cabrero I et al (2010) A novel tumor grading scheme for chromophobe renal cell carcinoma: prognostic utility and comparison with Fuhrman nuclear grade. Am J Surg Pathol 34:1233-1240

16. Cheville JC, Lohse CM, Sukov WR et al (2012) Chromophobe renal cell carcinoma: the impact of tumor grade on outcome. Am J Surg Pathol 36:851-856

17. Amin MB, Paner GP, Alvarado-Cabrero I et al (2008) Chromophobe renal cell carcinoma: histomorphologic characteristics and evaluation of conventional pathologic prognostic parameters in 145 cases. Am J Surg Pathol 32:1822-1834

18. Dannenmann SR, Thielicke J, Stockli M et al (2013) Tumorassociated macrophages subvert T-cell function and correlate with reduced survival in clear cell renal cell carcinoma. Oncoimmunology 2:e23562

19. Morra L, Rechsteiner M, Casagrande S et al (2011) Relevance of periostin splice variants in renal cell carcinoma. Am J Pathol 179: $1513-1521$

20. Sconocchia G, Spagnoli GC, Del Principe D et al (2009) Defective infiltration of natural killer cells in MICA/B-positive renal cell carcinoma involves beta(2)-integrin-mediated interaction. Neoplasia 11: 662-671

21. Boysen G, Bausch-Fluck D, Thoma CR et al (2012) Identification and functional characterization of pVHL-dependent cell surface proteins in renal cell carcinoma. Neoplasia 14:535-546

22. Luu VD, Boysen G, Struckmann K et al (2009) Loss of VHL and hypoxia provokes PAX2 up-regulation in clear cell renal cell carcinoma. Clin Cancer Res 15:3297-3304

23. Dahinden C, Ingold B, Wild P et al (2010) Mining tissue microarray data to uncover combinations of biomarker expression patterns that improve intermediate staging and grading of clear cell renal cell cancer. Clin Cancer Res: Off J Am Assoc Cancer Res 16:88-98

24. Patard JJ, Pouessel D, Bensalah K et al (2008) Targeted therapy in renal cell carcinoma. World J Urol 26:135-140

25. Skinnider BF, Folpe AL, Hennigar RA et al (2005) Distribution of cytokeratins and vimentin in adult renal neoplasms and normal renal tissue: potential utility of a cytokeratin antibody panel in the differential diagnosis of renal tumors. Am J Surg Pathol 29:747-754

26. Skinnider BF, Amin MB (2005) An immunohistochemical approach to the differential diagnosis of renal tumors. Semin Diagn Pathol 22:51-68

27. Zhou M, Yang XJ, Lopez JI et al (2009) Renal tubulocystic carcinoma is closely related to papillary renal cell carcinoma: implications for pathologic classification. Am J Surg Pathol 33:1840-1849

28. Sangoi AR, Ohgami RS, Pai RK et al (2011) PAX8 expression reliably distinguishes pancreatic well-differentiated neuroendocrine tumors from ileal and pulmonary well-differentiated neuroendocrine tumors and pancreatic acinar cell carcinoma. Mod Pathol: Off J U S Can Acad Pathol, Inc 24:412-424

29. Mete O, van der Kwast TH (2011) Epithelioid angiomyolipoma: a morphologically distinct variant that mimics a variety of intraabdominal neoplasms. Arch Pathol Lab Med 135:665-670

30. Eble JN (1998) Angiomyolipoma of kidney. Semin Diagn Pathol 15:21-40

31. Olgac S, Hutchinson B, Tickoo SK et al (2006) Alpha-methylacylCoA racemase as a marker in the differential diagnosis of metanephric adenoma. Mod Pathol: Off J U S Can Acad Pathol, Inc 19:218-224

32. The Cancer Genome Atlas Network (2013) Comprehensive molecular characterization of clear cell renal cell carcinoma. Nature 499:43-9 
33. Moch H (2013) An overview of renal cell cancer: pathology and genetics. Semin Cancer Biol 23:3-9

34. Shen C, Kaelin WG Jr (2013) The VHL/HIF axis in clear cell renal carcinoma. Semin Cancer Biol 23:18-25

35. Rechsteiner MP, von Teichman A, Nowicka A et al (2011) VHL gene mutations and their effects on hypoxia inducible factor HIFalpha: Identification of potential driver and passenger mutations. Cancer Res 71:5500-5511

36. Genega EM, Ghebremichael M, Najarian R et al (2010) Carbonic anhydrase IX expression in renal neoplasms: correlation with tumor type and grade. Am J Clin Pathol 134:873-879

37. Bui MH, Seligson D, Han KR et al (2003) Carbonic anhydrase IX is an independent predictor of survival in advanced renal clear cell carcinoma: Implications for prognosis and therapy. Clin Cancer Res: Off J Am Assoc Cancer Res 9:802-811

38. Moch H, Presti JC Jr, Sauter G et al (1996) Genetic aberrations detected by comparative genomic hybridization are associated with clinical outcome in renal cell carcinoma. Cancer Res 56:27-30

39. Schraml P, Struckmann K, Bednar R et al (2001) CDKNA2A Mutation analysis, protein expression, and deletion mapping of chromosome 9p in conventional clear-cell renal carcinomas: evidence for a second tumor suppressor gene proximal to CDKN2A. Am J Pathol 158:593-601

40. Varela I, Tarpey P, Raine K et al (2011) Exome sequencing identifies frequent mutation of the SWI/SNF complex gene PBRM1 in renal carcinoma. Nature 469:539-542

41. Pawlowski R, Muhl SM, Sulser T et al (2013) Loss of PBRM1 expression is associated with renal cell carcinoma progression. Int $\mathrm{J}$ Cancer J Int Cancer 132:E11-E17

42. Xu X, Hou Y, Yin X et al (2012) Single-cell exome sequencing reveals single-nucleotide mutation characteristics of a kidney tumor. Cell 148:886-895

43. Gerlinger M, Rowan AJ, Horswell S et al (2012) Intratumor heterogeneity and branched evolution revealed by multiregion sequencing. N Engl J Med 366:883-892

44. Kovacs G, Fuzesi L, Emanual A et al (1991) Cytogenetics of papillary renal cell tumors. Genes Chromosom Cancer 3:249-255

45. Speicher M, Schoell B, Du Manoir S et al (1994) Specific loss of chromosomes $1,2,6,10,13,17$, and 21 in chromophobe renal cell carcinomas revealed by comparative genomic hybridization. Am J Pathol 145:356-364

46. Argani P, Antonescu CR, Illei PB et al (2001) Primary renal neoplasms with the ASPL-TFE3 gene fusion of alveolar soft part sarcoma: a distinctive tumor entity previously included among renal cell carcinomas of children and adolescents. Am J Pathol 159:179-192

47. Argani P, Hawkins A, Griffin CA et al (2001) A distinctive pediatric renal neoplasm characterized by epithelioid morphology, basement membrane production, focal HMB45 immunoreactivity, and $\mathrm{t}(6 ; 11)(\mathrm{p} 21.1 ; \mathrm{q} 12)$ chromosome translocation. Am J Pathol 158: 2089-2096

48. Argani P, Lae M, Hutchinson B et al (2005) Renal carcinomas with the $\mathrm{t}(6 ; 11)(\mathrm{p} 21 ; \mathrm{q} 12)$ : clinicopathologic features and demonstration of the specific alpha-TFEB gene fusion by immunohistochemistry, RTPCR, and DNA PCR. Am J Surg Pathol 29:230-240

49. Green WM, Yonescu R, Morsberger L et al (2013) Utilization of a TFE3 break-apart FISH assay in a renal tumor consultation service. Am J Surg Pathol 37:1150-1163

50. Eichelberg C, Junker K, Ljungberg B et al (2009) Diagnostic and prognostic molecular markers for renal cell carcinoma: a critical appraisal of the current state of research and clinical applicability. Eur Urol 55:851-863

51. Algaba F, Akaza H, Lopez-Beltran A et al (2011) Current pathology keys of renal cell carcinoma. Eur Urol 60:634-643

52. Fisher R, Gore M, Larkin J (2013) Current and future systemic treatments for renal cell carcinoma. Semin Cancer Biol 23:38-45

53. Pena C, Lathia C, Shan M et al (2010) Biomarkers predicting outcome in patients with advanced renal cell carcinoma: results from Sorafenib phase III treatment approaches in renal cancer global evaluation trial. Clin Cancer Res: Off J Am Assoc Cancer Res 16: 4853-4863

54. Tang PA, Vickers MM, Heng DY (2011) Clinical and molecular prognostic factors in renal cell carcinoma: what we know so far. Hematol/Oncol Clin N Am 25:871-891

55. Minner S, Rump D, Tennstedt $P$ et al (2012) Epidermal growth factor receptor protein expression and genomic alterations in renal cell carcinoma. Cancer 118:1268-1275

56. Choueiri TK, Regan MM, Rosenberg JE et al (2010) Carbonic anhydrase IX and pathological features as predictors of outcome in patients with metastatic clear-cell renal cell carcinoma receiving vascular endothelial growth factor-targeted therapy. BJU Int 106: $772-778$

57. Heinzelmann J, Henning B, Sanjmyatav J et al (2011) Specific miRNA signatures are associated with metastasis and poor prognosis in clear cell renal cell carcinoma. World J Urol 29:367-373

58. Slaby O, Redova M, Poprach A et al (2012) Identification of MicroRNAs associated with early relapse after nephrectomy in renal cell carcinoma patients. Genes Chromosom Cancer 51:707-716

59. Nakada C, Tsukamoto Y, Matsuura K et al (2011) Overexpression of miR-210, a downstream target of HIF1alpha, causes centrosome amplification in renal carcinoma cells. J Pathol 224:280-288

60. Berkers JHMG, Wolter O, Beuselinck P, Schoffski B, Roskams P, Joniau TAD, Van Poppel S, Lerut , E.S.M.: MicroRNA-141 expression in clear cell renal cell carcinoma is linked with Sunitinib response. European Urology, Supplements

61. Redova M, Poprach A, Nekvindova J et al (2012) Circulating miR378 and miR-451 in serum are potential biomarkers for renal cell carcinoma. J Transl Med 10:55

62. Gamez-Pozo A, Anton-Aparicio LM, Bayona C et al (2012) MicroRNA expression profiling of peripheral blood samples predicts resistance to first-line sunitinib in advanced renal cell carcinoma patients. Neoplasia 14:1144-1152

63. Wu X, Weng L, Li X et al (2012) Identification of a 4-microRNA signature for clear cell renal cell carcinoma metastasis and prognosis. PloS One 7:e35661 